PNL-6587

UC-95d

$18 \mathrm{~J}$

\title{
Focus Group Discussions
}

Among Owners and

Non-Owners of Ground

Source Heat Pumps

\author{
B. F. Roberson
}

July 1988

Prepared for the U.S. Department of Energy under Contract DE-AC06-76RLO 1830

Pacific Northwest Laboratory

Operated for the U.S. Department of Energy

by Battelle Memorial Institute 


\title{
DISCLAIMER
}

This report was prepared as an account of work sponsored by an agency of the United States Government. Neither the United States Government nor any agency thereof, nor Battelle Memorial Institute, nor any or their employees, makes any warranty, expressed or implied, or assumes any legal liability or responsibility for the accuracy, completeness, or usefulness of any information, apparatus, product, or process disclosed, or represents that its use would not infringe privately owned rights. Reference herein to any specific commercial product, process, or service by trade name, trademark, manufacturer, or otherwise does not necessarily constitute or imply its endorsement, recommendation, or favor ng by the United States Government or any agency thereof, or Battelie Memorial institute. The views and opinions of authors expressed herein do not necessarily state or reflect those of the United States Government or any agency thereof, or Battelle Memorial Institute.

\author{
PACIFIC NORTHWEST LABORATORY \\ operated by \\ BATTELLE MEMORIAL INSTITUTE \\ for the \\ UNITED STATES DEPARTMENT OF ENERGY \\ under Contract DE-ACO6-76RLO $\$ 830$
}

\begin{tabular}{|c|c|}
\hline \multicolumn{2}{|c|}{ Printed in the United States of America } \\
\hline \multirow{2}{*}{\multicolumn{2}{|c|}{$\begin{array}{l}\text { Available from } \\
\text { National Technical Information Service } \\
\text { United States Department of Commerce }\end{array}$}} \\
\hline & \\
\hline \multicolumn{2}{|c|}{$\begin{array}{c}5285 \text { Port Royal Road } \\
\text { Springfield, Virginia } 22161\end{array}$} \\
\hline \multirow{2}{*}{\multicolumn{2}{|c|}{$\begin{array}{l}\text { NTIS Price Codes } \\
\text { Microfiche A01 }\end{array}$}} \\
\hline & \\
\hline \multicolumn{2}{|c|}{ Printed Copy } \\
\hline & Price \\
\hline Pages & Codes \\
\hline $001-025$ & $\mathrm{~A} 02$ \\
\hline $026-050$ & A03 \\
\hline $051-075$ & A04 \\
\hline $076-100$ & A05 \\
\hline $101-125$ & $A 06$ \\
\hline $126-150$ & $\mathrm{~A} 07$ \\
\hline $151-175$ & $A 06$ \\
\hline $176-200$ & $\mathrm{~A} 09$ \\
\hline $201-225$ & A010 \\
\hline $226-250$ & A011 \\
\hline $251-275$ & $\mathrm{~A} 012$ \\
\hline $276-300$ & $\mathrm{~A} 013$ \\
\hline
\end{tabular}


PNL -6587

UC-95d

FOCUS GROUP DISCUSSIONS AMONG

OWNERS AND NON-OWNERS OF

GROUND SOURCE HEAT PUMPS

B. F. Roberson

July 1988

Prepared for

the U.S. Department of Energy

under Contract DE-AC06-76RLO 1830

Pacific Northwest Laboratory

Richland, Washington 99352 



\section{MANAGEMENT SUMMARY}

Focus group discussions with recent buyers of heating and airconditioning systems were conducted to gain insight into the reasons for buying or not buying a ground source heat pump (GSHP). About half of the participants were GSHP owners and the others owned some other system. Key findings were:

- The factor that best differentiated GSHP owners from non-owners was the high level of involvement they had in the selection of their heating and air-conditioning system.

- By contrast, the non-owners typically reljed on the recommendation of a contractor or dealer.

- The GSHP owners were innovators and risk takers, but they believed that they were minimizing their risk by conducting an extensive information search.

- Because they conducted a thorough information search, GSHP buyers were more knowledgeable consumers than the buyers of other systems.

- The GSHP owners in these focus groups placed relatively low priority on purchase price and a high priority on product quality.

- Though many GSHP owners mentioned the high initial cost as a problem, few stated that cost was a barrier to purchase.

- Though most GSHP buyers made use of several subsidy programs, the extent to which they influence the actual purchase decision is not obvious.

- Future research it may be useful to segment and identify those who would buy a GSHP only if their purchase is subsidized.

- GSHP owners expressed an extremely high level of satisfaction with the performance of their system.

- There were no complaints about cooling performance.

- Some owners felt that heating performance in extremely cold temperatures could be improved. 
- Though operating costs were not always as low as expected, owners consistently felt that they were lower than the cost of alternative systems.

- It may be appropriate to position the GSHP as a premium priced, high quality system.

- This product position is generally consistent with the perception of current owners, and may appeal to a much larger target market.

- Research must define the competitive set of "top end" products.

- Research can profile the demographic and psychographic variables that distinguish between "top end" buyers and other buyer groups.

- In communicating to more cautious potential buyers it may be necessary to emphasize the reliability of the GSHP and to provide easily available means of confirming this.

- Local utility companies clearly play a pivotal role in the distribution of information about the GSHP to individual buyers.

- Consumers typically contact their local utility company at the start of their information search.

- Some utility companies have marketing and communication programs designed to increase penetration of GSHP's.

- Research among utility company managers could explore factors that may increase the involvement of utility companies in the marketing of energy efficient technology such as the GSHP. 


\section{CONTENTS}

MANAGEMENT SUMMARY ............................... i

INTRODUCTION . . . . . . . . . . . . . . . . . . . . . 1

COMMENTS ON QUALITATIVE RESEARCH . . . . . . . . . . 2

KEY ISSUES ........................... 3

METHOD ............................ 5

SAMPLE ......................... 5

PROCEOURE ......................... 6

RESULTS .......................... 7

THE PURCHASE DECISION . . . . . . . . . . . . . . . 7

INFORMATION SEARCH .................... 8

ATTRIBUTES . . . . . . . . . . . . . . . . . . . 9

OPERATING COST ........................ 9

PURCHASE PRICE . . . . . . . . . . . . . . . 11

SUBSIOY PROGRAMS . . . . . . . . . . . . . . . . . 12

ANCILLARY SYSTEMS . . . . . . . . . . . . . . . 13

MAINTENANCE . . . . . . . . . . . . . . . . . 14

COMFORT ................................ 15

SAFETY . . . . . . . . . . . . . . . . . 16

ENVIRONMENTAL ISSUES . . . . . . . . . . . . . . 17

THE POST-PURCHASE EVALUATION . . . . . . . . . . . . . 17

REACTIONS TO CONCEPTS . . . . . . . . . . . . . . . . 19

SAVE $\$ 50$ EVERY MONTH . . . . . . . . . . . . . . . 20

ONE THIRD THE COST ................... 20

CLEAN AND NATURAL ..................... 20 
NEW TECHNOLOGY PROVIDES ONE SYSTEM . . . . . . . . . . 20

COMMON ELEMENTS ................... 21

CONCLUSIONS AND RECOMMENDATIONS . . . . . . . . . . . . . . 23

TARGET GROUP DIFFERENCES ................. 23

RISK ORIENTATION . . . . . . . . . . . . . . . 23

INVOLVEMENT . . . . . . . . . . . . . . 24

TARGET MARKET PROFILE ................. 24

COMMUNICATION . . . . . . . . . . . . . . . . 25

THE TARGET AUDIENCE ................ 25

THE COMMUNICATION CHANNELS ............... 26

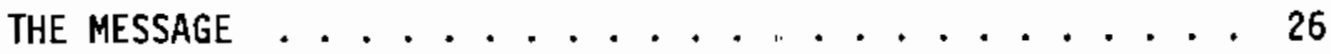

COST ISSUES ............................ 27

SUBSIDY PROGRAMS ..................... 27

PRODUCT PERFORMANCE ISSUES ................. 28

FUTURE RESEARCH . . . . . . . . . . . . . . . . 29

REFERENCES . . . . . . . . . . . . . . . . . . 31

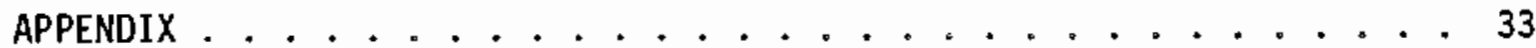




\section{INTRODUCTION}

This research was sponsored by the Office of Buildings and Community Systems and conducted by the Pacific Northwest Laboratory as part of an ongoing effort to enhance the commercial use of federally developed technology. Federal dollars have supported research on the development of ground source heat pumps (GSHP) for several years. Though several companies currentiy sell GSHP's for residential use, their share of the total heating and air conditioning business remains less than one percent. Large manufacturing companies with national distribution have not yet added GSHP equipment to their product line.

GSHP's use only about one half (Braud 1987) to one third (Bose 1987) of the energy needed to operate conventional furnaces and air conditioners. Consequent1y, a high level of market penetration by the GSHP offers direct benefits to both utility companies and individual users of the systems. Widespread use of these highly efficient systems will reduce both total energy consumption, and problems associated with high levels of energy use during peak periods. This will allow utility companies to delay capital expenditures for new facilities to meet the growing energy demand during peak periods. The cost effective use of electricity also reduces the likelihood of homeowners switching to a different fuel source for heating.

Consumers can benefit from this technology by being able to maintain comfortable household temperatures at a lower operating cost than that offered by competing systems. In addition, GSHP's have relatively low maintenance costs, and have virtually no adverse effects on the environment. Despite the obvious benefits, the GSHP does not yet play a major role in the heating and air-conditioning industry. One likely explanation for this is the relatively high purchase and installation costs of the GSHP.

It has been hypothesized that another reason the GSHP is not more widely used is because of inadequate national marketing programs. It is possible that the information being disseminated is not reaching the right people, that the information being provided is not persuasive, and/or the information is not being presented in a persuasive manner. Market research, such as the 
focus groups reported in this document, can provide insight and guidance on all of these issues. It is intended that this information will then be used to develop more effective marketing programs.

The GSHP is not the first heat pump technology to require assistance in conducting market research and market planning to obtain a meaningful share of the market. Henisee (1987) has documented the objectives and methods of one utility company in its efforts to increase penetration of air-to-air heat pumps. Their programs resulted in financial benefits to the utility and homeowners alike. Additional benefits were fewer complaints about high energy bills, and higher levels of consumer satisfaction with home comfort. Home builders involved in the project benefited because the homes with superior energy performance sold faster than other, less efficient, homes. Henisee noted that market research information was used to guide both strategic and tactical decisions regarding these programs.

Efforts to understand and develop marketing programs in a new area typically begin with qualitative research methods such as focus group discussions. The focus groups reported in this document represent a first step in gathering the necessary consumer information to successfully develop marketing programs that will lead to a high level of market pene = tration for the GSHP.

These focus groups were conducted to gain insight into consumer knowledge, perceptions, and expectations for the GSHP. This information will be used to guide decisions on appropriate directions for future product research, and viable positioning alternatives to enhance the market appeal of the technology. This information can be used to make a more useful product, and to show utility and manufacturing companies the profit opportunity they can have by investing in the development of GSHP technology.

\section{COMMENTS ON QUALITATIVE RESEARCH}

Qualitative research methods such as focus groups are not intended to be substitutes for sound quantitative methods. Since groups consist of a small number of selected respondents, results cannot be quantified and projected to a larger universe. Rather, focus groups are intended to provide insight into 
consumer perceptions of, and reactions to, the products and ideas of interest. Though it is intended that all meaningful perspectives will be represented in the groups, we are not in a position to determine the magnitude of importance that the various concerns have among the larger population (Advertising Research Foundation 1985; Greenbaum 1988).

The strength of the focus group method is in generating insight into individual perceptions and reasoning. Consequently, the analysis should facilitate understanding of the respondents and their reactions. Survey research that follows can clearly be improved through the learning obtained in focus groups. Understanding of consumer language, perceptions, and the range of responses to critical issues all contribute to superior quantitative research. The insight gained from qualitative research helps both in the development of testable hypotheses and in interpreting the data.

\section{KEY ISSUES}

Participants were asked to address several areas of specific interest. The major topics for discussion were as follows:

- The decision-making process, including conducting an information search and finally selecting a specific system.

- Exploration of the importance of various product attributes.

- The role of pricing and subsidies on the purchase decision.

- Differences in the decision processes of GSHP buyers vs. nonbuyers.

- Reactions to specific GSHP features.

- Reactions to several marketing concepts. 


\section{$\underline{\text { METHOD }}$}

The focus group method consists of loosely structured discussions among small groups of individuals. The sample for these discussions is usually selected to ensure that a11 relevant perspectives are represented. This section contains a detailed description of the sample selection and research procedures employed in this study.

\section{SAMPLE}

Respondent names were obtained from a variety of sources. Owners' names were obtained from lists of GSHP purchasers provided by local utilities and equipment dealers. Some aware non-owners names were obtained from utility lists of persons who contacted them requesting information on various systems. Other aware non-owners were contacted via random digit dialing. All of these persons were screened for eligibility in a telephone interview and invited to attend the discussion.

The participants were screened to ensure that they were all heads of household, between 18 and 65 years old, who had purchased a new heating and air-conditioning system in the previous three years. For each group of respondents a screening quota was set for at least three participants who purchased a new home, and three who bought a new heating and air-conditioning system while remodeling their home. Each respondent said that he or she was involved in the decision regarding the selection of their current heating and air-conditioning system.

The focus group in Indianapolis, Indiana included five GSHP owners and two aware non-owners. Three of the respondents were female and four were male. In Baton Rouge, Louisiana, one group consisted of seven GSHP buyers and one aware non-buyer. All participants in this group were male. The other group consisted of five aware non-buyers, four of whom were female. 


\section{PROCEDURE}

Respondents were contacted and screened through a telephone interview. Those agreeing to attend were sent a follow-up letter as a reminder. Respondents were informed that they would receive a $\$ 35$ cooperation fee when they had completed the interview.

Four focus group discussions were planned. However, poor local weather conditions in Indianapolis, Indiana resulted in low participant turnout for the first group discussion. In that market a one-on-one interview and one group discussion with both GSHP owners and non-owners was conducted. As planned, two separate focus groups were conducted in Baton Rouge, Louisiana. The group in Indianapolis was conducted on April 6, 1988, and the groups in Baton Rouge were conducted on April 7, 1988.

These markets, which were selected upon recommendation from officials of the International Ground Source Heat Pump Association (IGSHPA), are recognized to have relatively high penetration of GSHP's. In addition, Indianapolis requires more energy to heat homes than to cool them, and Baton Rouge requires more energy for cooling. Thus, homeowners in these areas would likely represent the full range of system performance concerns.

The discussions took place in standard focus group facilities. The conference rooms used had visible microphones at the table and a one-way mirror along one wall. Respondents were informed that the discussion would be tape recorded, and that observers were viewing the discussion from behind the mirror. The discussions lasted from one and one half to two hours.

Focus group sessions entailed a semi-structured discussion format led by a moderator. The moderator introduced topics for discussion, asked questions to probe key comments, presented concepts to stimulate reactions, and made sure the discussion dealt with relevant topics. Respondents were free to comment on the topic in their own terms and present their opinion. Respondents were also asked to evaluate four marketing concepts for GSHP's. The order of presentation of the concepts was varied for the different groups. The complete stimulus concepts can be seen in the appendix. 


\section{RESULTS}

In this section consumers' comments on the factors that contributed most to their purchase decision are presented, along with their post-purchase evaluation of their heating and air-conditioning systems. Consumers' reactions to four marketing concepts will also be discussed.

The consumers we spoke to generally discussed their current heating and air conditioning systems with an implicit comparison to other systems with which they have had experience. Consequently, evaluations about system efficiency have been explained relative to previous systems in the same house, other systems in other homes respondents had owned, and even relative to the of heating and air-conditioning systems in the homes of friends and neighbors. Though the basis for evaluation was not a7ways systematic, most respondents held strongly to their beliefs about the strengths and weaknesses of their systems.

While GSHP owners invested a great deal of intellectual energy in their purchase decision, they seem to have invested an equally large measure of emotional energy. Consequentiy, a lot of objective information was sought out by most GSHP buyers prior to their purchase decision, but the postpurchase evaluations seemed to be driven primarily by personal expectations, feelings, and priorities. An overview of the discussions follows.

\section{THE PURCHASE DECISION}

The intensity of feelings about the performance of their heating and air conditioning system was especially strong among owners of GSHP's. This intensity can be at least partially understood by looking at these consumers' actions before they bought their systems.

From the moment that the need for a new systems was identified, GSHP owners took a more active role than did non-owners. The owners' high level of involvement may be related to two perceptions that differ from the nonowners. First, owners typically felt that the type of heating and airconditioning system they had was very important. Second, owners believed that they were the person most able to determine which system would be best 
for them. Conversely, non-owners generally bought their home without much reflection on the type of heating and ajr-conditioning system, and accepted contractor recommendations without much critical evaluation. In general, GSHP owners were much more involved in the decision to buy a specific system than were non-owners. They made a personal commitment to the selection of the "right" system. As one respondent explained:

-. "I was scared... my husband said, 'find out all you want about it and we'11 get whatever you want'...that's a lot of burden... What if it collapses? What kind of guarantee do I have and what warranties go with it? How do you know if a line underground breaks?... There are all kinds of [questions], and I found the answers."

Non-owners tended not to make any decision regarding the heating and air-conditioning system. A common statement was that they had the system that came with the house, and that feature was not an important factor in their selection of the house. Consequently, the choice of the heating and air-conditioning system was typically made by a previous owner, or by a contractor.

-- "Our [heating and air-conditioning system] came as part of a package deal when we built our house."

-- "I took [the contractor's] word for what was best."

\section{Information search}

GSHP owners conducted a much more extensive information search than did non-owners. This search was typically initiated with a request for information from the local electric company. Awareness of the GSHP and interest in it may have been started by advertising on the topic or an article in a magazine. No one said the system was recommended by a friend, but then, very few people have the systems yet. Several people then approached sales representatives of several contractors and heating and ajr-conditioning dealers. Some obtained a list of owners from the utility company and contacted these people about their system.

-- "Where you learn more, is not from the electric company...just go to the people who have them in."

This high involvement in the decision resulted in a much better informed group of consumers. These people may have seen demonstrations of the system, 
and were knowledgeable enough to compare the performance of various systems on a number of dimensions. While non-owners often readily accepted the advice of contractors and dealers, GSHP owners were likely to question the accuracy of the information they received. Several people were quick to point out that both gas and electricity claim in their advertising to be the most efficient fuel for heating. GSHP owners typicalty demanded proof.

Though virtually all owners started their information search with the local electric utility, they were uneasy with the reasons that the utility company was encouraging them to get an efficient system that would consume less electricity. Thus, while the utility company seemed the logical place to get information on heating and air-conditioning alternatives, the credibility of this information was questioned because of an apparent conflict of interests. Quantitative research may determine whether this issue should be addressed in future communication programs.

\section{ATTRIBUTES}

Homeowners considered a relatively small number of attributes and issues important. In selecting and evaluating heating and air-conditioning systems, the key attributes identified in these focus groups were:

- operating cost

- purchase price

- subsidy programs

- ancillary systems

- majntenance

- comfort

- safety

- ecology/environment issues

Operating Cost

For GSHP owners and non-owners alike, one of the most salient features of their current heating and air-conditioning systems is operating cost. GSHP owners consistently mentioned cost factors as features of their systems that they liked. Both low operating cost (i.e., monthly heating and cooling costs), and low maintenance costs were cited. 
Several of the GSHP owners said that they had perceived the operating costs of their previous systems to be exorbitant. It was this perception that led them to investigate the GSHP and other efficient alternatives. Some illustrative comments include:

-. "I wanted to get away from electric baseboard heat. That's the worst kind of heat you can have, I think...Our bills were 500 [dollars] and something a month."

-. "I didn't know what central air-conditioning was like...we couldn't afford to run our air-conditioner."

- " The idea of transferring heat from one point to another is much more efficient than creating heat."

Fuel expenditures are a fairly large portion of a homeowner's variable costs. Consequently, energy use is a large area of opportunity for controlling costs. For all homeowners, the cost of heating and airconditioning their home is one of the few monthly expenses that they can really affect. In addition, the previous decade of increasing fuel prices seems to have acclimated these consumers to the idea of doing things to reduce fuel expenditures. As a result, most of the consumers we spoke with were sensitive to the issue of monthly fuel costs to keep their house comfortable.

Some owners felt that the GSHP saved them as much money as they expected. Others acknowledged some savings, but said that it was not as much as they were led to believe. Even this, however, did not cause anyone to evaluate the system negatively. Rather, evaluations merely became a bit less positive. Owners still felt they obtained meaningful savings and felt that they had the best system available.

The GSHP owners seemed to take a more aggressive, action-oriented view of this situation than did non-owners. Respondents in both groups complained about their high monthly energy bills, but the GSHP owners believed that they had done, or were doing, all they could to minimize their costs. Though both groups expressed some sense a lack of control over their utility costs, GSHP owners clearly felt that they had taken control to the greatest degree possible. 
Lower operating costs provide actual financial savings over the longterm, but the lower bill also represents other valuable things. To GSHP owners, the lower monthiy bills may serve as evidence that the "best" system was chosen, and may support the owners' perception that they are less dependent on the local utility company.

While operating cost is a major contributor to the decision to buy a GSHP, this is not a purely financial decision. Buyers undoubtedly felt that they were making the best economic decision when they chose the GSHP. However, it is unlikely that the decisions of these people were primarily motivated by financial considerations. Rather, these buyers appear to have been influenced by the opportunity to exercise personal control over their situation. Future research should assess the impact of advertising that touches on the psychographic variables associated with the desire for personal control and the self image of target buyers.

\section{Purchase Price}

The anticipation of a lower operating cost had to be balanced against the higher purchase price of the GSHP compared with alternative systems. The additional cost of installing GSHP systems varied greatly; ranging from one thousand to five thousand dollars more than that of other systems considered by these consumers. Not surprisingly, consumers identified the additional up-front cost as a neyative attribute.

-. "[one]...prob]em, the up-front cost. That kind of scared me away because I'm not sure the pay-back period would be small enough to be worthwhile."

-. "If it's done right, there's almost no disadvantages other than cost."

-. "The on7y disadvantage of mine is the initial cost. It cost me about $50 \%$ more than other systems cost."

It is interesting that GSHP owners talked about the initial cost of their system a lot more than did non-owners. As with most aspects of this decision, the owners seemed more knowledgeable on this topic, and in fact, they may have thought this issue through more than non-owners given that they made a decision to buy the more expensive system. However, owners gave the 
distinct impression that it was important to them to justify their decision. Again, this suggests that GSHP buyers felt it was important to get the "best" system, to make the "right" decision.

Compared with owners, non-owners were much more resistant to the idea of spending so much more on the GSHP. Though there may be a big difference in the way these groups view the product, there are other viable hypotheses. It may be that owners were equally resistant to the high purchase price, but after conducting their investigation, they decided the GSHP was worth the expenditure.

\section{Subsidy Programs}

A number of programs are available to help offset the higher cost of installing a GSHP. Virtually all of the GSHP owners took advantage of one or more of these programs. The range of subsidy programs includes tax credits, rebates from utilities, free installation of the loop, and low-interest loans. For some people a subsidy to offset all or part of the high initial cost was critical in deciding to get the GSHP. Some of the comments were:

-. "We had to get a loan out for this...they installed the loop for nothing and that knocked over $\$ 1000$ off the price. That really made a difference for us.... our loan was approved.... I think if we could have gotten a loan at $61 / 2 \%$, that would have been just as good."

-- "The REMC installed the ground loop for us. That knocked about $\$ 1000$ off the price."

The extent to which these programs influenced the decision to purchase the GSHP system is not clear, since it was evident that many of the buyers would have bought a GSHP even without a subsidy. In the words of one owner:

-. "I already decided to go geothermal...then I called the electric company and said, 'Hey, do you got anything you're going to bribe me with to go electric?' and he said, 'Yeah, we've got this $\$ 400$ rebate thing."

This same respondent also received a free extended warranty on his compressor from the utility company, and learned of and used a state tax deduction for purchasing the system that amounted to several hundred dollars in additional 
benefits. This consumer made use of three subsidy programs worth well over $\$ 1000$, even though he chose to buy the GSHP before he even knew of the subsidies.

It should be noted that many of the GSHP owners identified the high initial cost of their system as a feature they disliked, but very few said that they would not have bought the system without the subsidy. Determining when and what types of subsidies are really necessary should be pursued in future research so these marketing programs can be targeted more effectively. Ancillary Systems

The GSHP has two ancillary systems. Although both systems are optional, a]l owners are likely to have one or both of them. The first system is a "desupercharger" or "desuperheater," which reduces costs for hot water in the winter and virtually eliminates this cost in the summer. Basically, a small loop is added to the system to pass heat through the desupercharger into the hot water tank. The desupercharger works with extremely high efficiency when one is air-conditioning. This system is considered a valuable additional benefit by the owners who have it.

-- "[The desupercharger has] a one-year payback, so you can't afford not to get it."

.. "In the summer my water is heated virtually for nothing. That was a big selling point on it."

-- "You can run hot water and it won't cost you any more, and you won't run out of it."

Though the desupercharger is less efficient when one is heating than when air-conditioning, it does reduce hot water costs in all seasons. However, none of the owners in these discussions knew that the desupercharger worked when they were heating. Communication of this fact could add to the perceived value of the system even beyond the already highly positive appraisal. The few owners who did not own a desupercharger did not know about it. When we discussed it, they seemed very interested in getting one.

The other system that most GSHP owners had was some kind of back-up heater. Obviously, a back-up heating system was more important for people living in Indianapolis than for those in Baton Rouge. Exact conditions vary, 
but at some point, the GSHP cannot produce enough heat to keep the home at the desired temperature.

One woman, whose first system was ruined by a fautty wood-burning stove back-up system, had no back-up on her second system. The rest of the owners who had a back-up heater used electric resistance heat. When the back-up heater was on, consumers typically felt there was something wrong with their system or that it was too smal1.

-- "That was one of the drawbacks to me, the back-up heat coming on so much."

-. "Our back-up system kicks on quite a lot...more than I thought it should. When we got the system we weren't even going to put the back-up system in. If we hadn't, I shudder to think what would have happened."

However, one owner insisted that his dealer install a system that was half a ton larger than the dealer recomnended. He stated that:

-- "Our back-up ran only two hours for the whole year. That's what I would guess."

Though this statement drew envious comments from the other participants, informed persons outside the group state that too large a system will result in less effective air-conditioning performance.

\section{Maintenance}

System maintenance really has two basic components: cost and convenience. Respondents familiar with air-to-air heat pumps were especially attuned to these maintenance issues, since, it seems the air-to-air systems required more maintenance than anticipated.

-. "Another advantage I've noticed... is that the maintenance is a lot less because your equipment is inside in a controlled environment and you have less wear and tear."

-- "When [I] had the unit on the outside...I had to get it cleaned every so often."

The fact that all equipment is indoors seemed especially important in Baton Rouge. The very wet weather conditions were thought to be especially hard on the outside heat pump equipment. This suggests the possibility of a new 
positioning alternative and the potential value of focusing marketing efforts on coastal and other areas that receive a lot of rain.

Another maintenance issue relates to the relatively long expected life of GSHP's relative to air-to-air heat pumps. One owner reported that he did not know air-to-air heat pumps had an expected life of only about ten years untiT his quit working after nine years. Though he wanted an efficient system, he did not want to replace it every decade. He selected the GSHP after he found that natural gas was not avajlable in his area. The anticipated 1 ife of the equipment was an important contributor to his decision.

The air-to-air heat pump requires more routine maintenance and earlier replacement of equipment than alternatives. The GSHP offers the high efficiency associated with these systems but without the maintenance problems. It would be useful to examine the value of positioning the GSHP as an alternative to air-to-air heat pumps. This narrower scope may help target more innovative, efficiency-oriented consumers at the top end of the heating and air-conditioning market.

\section{Comfort}

The GSHP owners were generally satisfied with the comfort provided by their systems. However, as pointed out earlier, they seem willing to forego some level of heating comfort to keep monthly bills lower. Nonetheless, performance of the GSHP's seemed to be really exceptional in providing airconditioning while keeping costs down. Though some owners were comparing with antiquated or, perhaps, room air-conditioners, the even temperature throughout the house was an important performance improvement.

-. "Within seconds every room is comfortably cool. Its wonderful, I love it."

-- "I'm comfortable. In every room I go into I'm comfortable."

In terms of heating comfort, the GSHP again rated well on uniform distribution of heat around the house. However, the perception of the comfort level of the warm air at the register varied as a function of the individual's reference point. Former owners of air-to-air heat pumps thought the GSHP produced warm, comfortable air at the register. Conversely, former 
owners of conventional electric or gas systems gave a less positive evaluation. Some typical comments follow:

-. "Its not a warm, hot heat like oil. You don't stand on a register and dry your boots out. Its a drafty heat, but its comfortable... I never had that with baseboard heat... I'd go upstairs and put a sweater on and downstairs I'd burn up."

-- "What I like is the warmer air you get out of the register [compared to that generated by the air-to-air heat pump]."

It is interesting that the Baton Rouge owners felt that the heating system was exceptional. Thus, this system would be especially effective in northern areas where heating is a more important function than air-conditioning. Whereas, owners in Indianapolis felt that the air-conditioning performance was exceptional, so the system would be especially effective in southern areas where that is more important than heating performance.

\section{$\underline{\text { Safety }}$}

Though some people felt strongly about safety as a critical attribute in selecting a heating system, for most it was a minor concern. There was a widespread belief that most systems are safe. The concerns that did exist were specific to gas heat.

-- "The thought of something burning in the house like liquid propane...I would always worry."

-- "We looked at the high-efficiency gas furnace before we went with ground source, geothermal. I didn't like it because you couldn't tell if there was a leak... if somebody lit a match it would be all over."

The safety concerns seemed based on bad experience with an old gas stove or furnace several years earlier. It would be very difficult to convince these people that gas could be safe.

No safety concerns at all were expressed for other heat ing systems. Surprisingly, no one mentioned the threat of fire with wood-burning stoves or fireplaces. 


\section{Environmental Issues}

Several owners said that they liked the fact that their system was not detrimental to the environment like other systems. This included the more efficient use of electricity and the idea of using "natural" heat and cooling from the earth. Several owners also included "noise control" as an environmental issue. They talked about the noise pollution in a neighborhood where air-to-air heat pumps are common, and took satisfaction in the knowledge that they were not contributing to this problem. Several respondents also noted that their home was more attractive with the GSHP, since they no longer had an outside unit to affect the appearance of their home and yard.

Non-owners gave the environmental issue a lower priority.

-- "Its important to me, but not as much as costs"

-. "I feel great for the environment, but I'm not willing to pay too many bucks for it."

A related issue is how the system affects the atmosphere inside the house. The GSHP is clearly perceived as keeping the indoor air clean, and owners felt good about this. This is clearly a secondary benefit. This issue was not spontaneousiy mentioned, and no one seemed to feel very strongly about it.

\section{THE POST-PURCHASE EVALUATION}

The GSHP owners were extremely satisfied with their systems. All of the owners except one said they would buy the same system again if they had to make that decision again. The one exception said he bought his GSHP in the first place only because natural gas was not available in his area, and that was still what he preferred. Nonetheless, the GSHP remained his second choice. Some general comments on the system include:

-. "I love it."

-. "I really like the cooling system of it."

-. "Geothermal is warmer [than air-to-air heat pumps] as far as the feel of the air coming out of the register." 
-. "You can go to any room of the house and its comfortable."

-. "Its [economic savings are] proven beyond my expectations."

As stated above, the GSHP owners made a rather large commitment to their selection. This commitment was psychological as well as financial. Consequently, it may have been especially important for these people to perceive the system as performing well. Several respondents described problems or performance below what was expected, but they generally minimized the importance of the problems. This phenomenon is illustrated in the comments of one woman who said:

-- "Our bill for two months were quite a bit higher than what the projected analysis was, and that was discouraging...every time I walked past my thermostat my blue light was on [indicating the back up system is active]."

Though this system was not performing as well as she had expected, this woman took personal responsibility for the problem. She went on to explain that she needed to learn when to shut off the back-up system to keep the bills down.

Another respondent whose first GSHP was ruined by a faulty back-up heating system (not installed by professionals) also minimized the fact that the GSHP did not keep the house at the desired temperature.

-- "We haven't put a back-up system on. On the few days when it gets a little cold inside the house, we just put more sweaters on.

Those days pass and then we're okay."

Owners perceived the importance of these problems with the system in heating the home as minor, and they seemed to contribute very little to the overall satisfaction with the system. What's more, poor heating performance was a probiem only in the Indianapolis market. Consumers in Baton Rouge were very pleased with the heating performance of their GSHP. It seems likely that the perceived efficacy of this system will always be higher in warmer areas than in colder areas. One should consider the feasibility of improving the heating performance of the systems to minimize or eliminate performance deficits in extremely cold weather. 
The respondents' additional comments indicate that the performance of GSHP's is superior to that of other systems on the attributes that GSHP owners consider most important. For example, the cooling function of the GSHP was applauded by all owners with no reservations. Operating costs were reduced and comfort was retained or even improved over that provided by previous systems. In addition, previous owners of air-to-air heat pumps were very pleased by the lack of outside noise when the system was operating.

The priority placed on various heating and air-conditioning features is different for GSHP owners than for non-owners. Many owners had what they considered to be inefficient systems in the past and were determined to get a system with lower operating costs. Thus, GSHP owners generally had a longterm view in examining the alternatives. In addition, they were typically willing to expend time, energy, and money to ensure lower operating costs in the future.

By contrast, non-owners put much more emphasis on having a trustworthy, reliable system. Though they also want lower operating costs, they see the GSHP as still somewhat experimental. Non-owners expressed a reluctance to invest in the GSHP.

.. "I still don't know about geothermal... what I have now works, its not bad. Before I would venture on unknown territory I would have to know a lot more."

In fact, even after having the system in their home for some time, severa] GSHP owners expressed anxiety about the fact that the reliability of this new technology was not thoroughiy proven. While a five or ten year warranty on the compressor helps set owners at ease. They know that they are innovators in owning these systems, and despite their careful research of the product, they know that unpredictable problems in the system could occur.

\section{REACTIONS TO CONCEPTS}

Consumers were asked to evaluate four marketing concepts (see appendix). These concepts were written to reflect four distinct positioning alternatives. They emphasized different benefits of GSHP's and different ways to describe those benefits. Responses are generally consistent with findings 
from the discussion of attributes, but each concept merits brief discussion. The four concepts also had some common elements, such as the description of how the systems function. These elements will also be discussed.

\section{Save $\$ 50$ Every Month}

This concept statement claimed that the GSHP would save owners an average of $\$ 50$ per month on their heating and air conditioning bills. Respondents found this claim difficult to believe. With so much variety in housing, respondents felt the validity of the claim could not be judged without information on specific homes. Though owners typically felt that they personally were saving more than $\$ 50$ per month on average, they did not feel that this statement was believable as a blanket claim for the system. One Third the Cost

This concept stated that the GSHP was so efficient it used only one third as much energy as conventional systems, and consequently, cost only one third as much to heat and $\operatorname{cool}$ a home. Respondents thought that giving a relative efficiency level rather than a specific: dollar figure was more believable and more appropriate for a variety of house types. Some people stated that the claim of using one third the energy of conventional systems was probably too strong. A claim of one half was consistent with the experience of most GSHP owners, and was therefore more believable and didn't sound like a sales pitch.

Clean And Natura1

This statement described the GSHP as the natural way to cool and heat one's home, and emphasized that it does not pollute the environment or the home as much as other systems. Some owners said this was one of the reasons they bought their GSHP. Others felt that this was a good feature, but it did not drive their purchase decision.

New Technology Provides One System

This concept emphasized that since the GSHP is an integrated system that both heats and cools, this new technology could efficiently replace separate conventional heating and air conditioning systems. The idea of a integrated system appealed to some, but the fact that this is based on new technology 
was more of a concern than a comfort. People wanted proof that this technology would work over the long term.

\section{Common Elements}

The four concepts all had distinctly different product positions, but they also shared a common description of how the GSHP works. The common elements were:

1. The system works by transferring hot or cold air from the earth to your home through an underground pipe.

2. The system can be easily switched from heating to cooling.

3. The energy saving will pay for the extra cost of installing the underground pipe in less than three years.

The description of the pipe used to transfer heat was easily understood by respondents and was appealing. One owner commented that the idea of transferring heat rather than creating it just made sense at an intuitive leve1. Neither owners nor non-owners expressed any concern about having buried pipe in their yard. Since the pipe was several feet underground, no one worried about accidentally digging it up. The only concern about the pipe was the expense of installing it.

The ease of switching the system to either heating or cooling was very appealing. This comment also supported the perception that temperature control would be evenly distributed. Several owners said that no switching was required. The thermostats they had were automatic, and their systems heated or cooled as needed to maintain the set temperature.

One respondent said the claim that the savings would pay for the extra cost of installing the loop was deceptive, not because the claim was untrue, but because that is only a part of the system cost. He felt that payback schedules should deal with the total cost of the system, not with the incremental cost of the GSHP compared with other systems. However, other respondents did see value to this claim and felt that it was appropriate.

-- "It seems to me the [GSHP] system is comparable to other systems. The difference is the underground pipe. Once its paid off there is no difference. Then you save because its cheaper to run." 


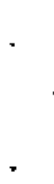




\section{CONCLUSIONS AND RECOMMENDATIONS}

These results support the development of hypotheses and recommendations for next steps. In this section a number of information needs have been identified and general methods for acquiring the information are outlined. Though the issues discussed in this section are highly interrelated, they have been separated into distinct topic areas to facilitate analysis.

\section{TARGET GROUP DIFFERENCES}

Though these focus group results cannot support the quantification of distinct target groups, they do identify some of the key demographic and psychographic differences between some groups as observed in the discussion. In this section key variables are discussed and research options are presented.

\section{Risk Orientation}

Not surprisingly, GSHP owners expressed much greater comfort with this novel system than did non-owners. The GSHP owners were innovators and risk takers, but they believed that they were taking a calculated risk, not a gamble. The objective information obtained through the information search helped them quantify and reduce the perceived risk of the new technology. The GSHP owners were confident of their own ability to understand and integrate this information.

These innovators are most open to persuasive presentations based on the results from experiments that compare actual energy use of various systems. They are willing to expend the time and energy to critically evaluate such reports. It would al so be important for these people that sales representatives who deal with them are well informed. Prior to the purchase decision, these people are likely to ask difficult questions about the systems. If sales people cannot answer their questions, confidence in the systems may be undermined.

Results from the focus groups reported here clearly supports the hypothes is that non-owners are a more conservative, risk-averse group than are owners. If marketing programs are to address the concerns of this 
potential target market it may be prudent to change the message. In communicating to this group, it may be necessary to emphasize the reliability of the GSHP and to provide easily available means of confirming this. One option would be for advertising to make extensive use of testimonials from current GSHP owners. It seems that this format would be persuasive for both innovative, risk-oriented consumers and their more conservative, risk-averse counterparts.

\section{Involvement}

The factor that best differentiated GSHP owners from non-owners was the level of involvement they had in the selection of their heating and airconditioning system. Though the causal direction is not obvious, high involvement was clearly associated with other decision-related factors.

A high level of involvement with this decision was associated with the perception that it was an important decision, and the belief that one can and should exert personal control in the selection of a heating and airconditioning system. Consequently, compared with non-owners, GSHP owners generally conducted a more extensive information search and became much more knowledgeable consumers.

By contrast, the non-owners were reluctant to invest a lot of time and energy in this decision, and typically relied on the recommendation of a contractor or dealer. A critical task in marketing GSHP's to this population will be to increase their involvement and interest in this decision. Only then will information about product superiority be persuasive.

\section{Target Market Profites}

The GSHP cannot be all things to all people. There is clearly a need to position the product to meet the needs of a sizable target market. Compared to the non-owners, the GSHP owners in these focus groups placed low priority on purchase price and a high priority on product quality. High quality was generally equated with low maintenance and operating costs, long expected life of equipment, low noise level, and clean operation. There is a need to assess the size of the market for "top end" systems. This will help define what other systems the GSHP competes against. 
Once the set of competing products is identified, one can profile the size and characteristics of the target population of potential buyers. Quantitative market research can help answer a multitude of questions. For example, it is important to know what percent of buyers are interested in the top end systems. Further, there is the question of whether top end buyers differ from other buyers in term of demographic and psychographic variables. In addition, it is important to know the nature of geographic differences in the levels of acceptance of this technology. Acquisition of this type of information will support more effective targeting of marketing programs to people most likely to be interested in the GSHP technology. Information on all of these issues can have profound influence on the success of programs intended to support greater penetration of this technology.

\section{COMMUNICATION}

In discussing communication issues there are a few basic questions that must be addressed in order to be effective. Who is the target audience? How can you reach the target audience? What is the message you want to convey? What is the most effective way of expressing the message?

The Iarget Audience

To inform and persuade an audience it is critical to know who that audience is. Very few products have broad enough appeal that an undirected, general description of them will interest any large segment. Rather, the message must be tailored to the specific audience. The need to segment the population of potential buyers, and some general research methods for doing this were discussed above. It is sufficient to say that the importance of defining a target market cannot be overstated.

Of course, an alternative market strategy would be to focus communication efforts on the bujlding contractors and heating and air-conditioning dealers who make this purchase decision for many home buyers. But experience has shown us that they may be more interested in keeping initial costs down than they would be in providing the most efficient heating and airconditioning system. The feasibility of providing business incentives to builders for installing GSHP's in "spec" homes should be examined. It would 
also be helpful to determine what effect evidence of a consumer demand for efficient systems would have on builder decisions.

\section{The Communication Channels}

Local utility companies clearly play a pivotal role in the distribution of information about the GSHP to individual buyers. Support has been offered through both personal contacts and mass communications such as television advertising. Since consumers consistentiy approach the utility company to get energy information it may be useful to develop this communication channel further. Approval of the GSHP system by the local utility is a source of credibility for this new technology. Consequently, a close working relationship between utility companies and GSHP retailers seems important.

Though the local utility was typically the starting point in the information search, owners questioned the credibility of this source. They wonder why the electric company wants to help them reduce their electric bills. Marketers should consider addressing this issue in their sales literature.

It would be advisable to initiate a national annual tracking study to monitor the changes in consumer awareness and understanding of GSHP and other heating and air-conditioning options. This research would show what the relative importance of various information sources were, and indicate what consumers were learning about the systems. The effectiveness of various programs could be assess, which would support wiser decisions about the development of future programs.

\section{The Message}

Among GSHP owners in these groups assurances of high quality seemed to be the most convincing information. A number of factors were observed to be indicators of quality. The primary cues of quality were low monthly operating cost, calculated lifetime costs superior to alternatives, quiet and clean performance, and constant household comfort. It is possible that the relatively high initial cost is interpreted as a cue of high quality as well. 
As one attempts to broaden the appeal of this product to other target groups it may be necessary to alter the message. For example, if there is a need to increase assurances of the reliability of the GSHP, some of these same product features that imply quality can be emphasized to highlight reliability. However, one must identify the target market, and determine what their priorities are before designing the message.

\section{COST ISSUES}

Consumers generally thought the GSHP was too expensive, but this was at least partially offset by the variety of subsidy programs that helped bring the initial cost down. It is worth noting that while many owners mentioned the high cost as a problem, few stated that this would have been a barrier to purchase. Rather, those who purchased GSHP's seemed compelled to find evidence that they had made the right decision. Purchase price did not seem to be the primary driving force behind the purchase decision. They seemed more motivated by a desire to make the "right" decision. Consequently, information on operating costs, energy efficiency, quality, and durability of the system was important to these people.

This information suggests the viability of positioning the GSHP as a top-end, quality product. Efficient use of energy could easily, and appropriately, be defined as an indicator of quality. Other performance cues such as cleanliness, quietness and comfort could also be defined as indicators of quality.

\section{Subsidy Programs}

Most GSHP buyers took advantage of several subsidy programs, though the existence of the subsidy may not have been the driving force behind the purchase decisions. Since owners often focus on system costs over its total lifetime, marketers may want to focus less on purchase price. There is clearly a need for quantitative research to determine the best type and delivery format for subsidy programs to most effectively increase penetration of this technology.

To successfully design and evaluate various subsidy programs it would be valuable to identify three groups of consumers: 1) those who would buy a 
GSHP even with no subsidy, 2) those who would buy a GSHP only if their purchase price is reduced through a subsidy, and 3) those who will not buy a GSHP. Subsidies have historically been used by all buyers. Untargeted subsidies are inefficient because they are used extensively by people who would make the purchase anyway. They should be designed to be used extensively by those in group 2, and only minimally by those in group 1 . There is clearly a need to define the demographic and psychographic variables that differentiate these buyer groups. This information can then be used to develop more effective marketing and subsidy programs.

\section{PRODUCT PERFORMANCE ISSUES}

The GSHP owners displayed extremely high satisfaction with the performance of their systems. They consistently felt that their operating expenses were lower than they had ever been before, and lower than they would be with a different type of system. Although some owners said their operating expenses were not reduced as much as they expected them to be, they were still satisfied with the level of cost reduction obtained.

There were no complaints at all regarding the air-cooling function of the GSHP. However, several owners said the heating performance could be improved. Specifically, the system was not able to heat the house adequately in extremely cold weather. Several people felt their back-up system came on too often, resulting in higher operating costs for the total system. However, there was a general tendency to minimize the importance of these failings. They did not seem to detract significantly from the overall satisfaction with the system.

Quantitative market research should be used to establish the weight of this and other variables on the overall satisfaction among various target buyer groups. Since testimonial support for these systems seems an influential type of information, it may be especially important to maintain high satisfaction as penetration of this product is marketed among new buyer groups. 


\section{FUTURE RESEARCH}

This analysis suggests two fruitful directions for future market research to facilitate greater market penetration of the GSHP technology. First, there is a need for reliable information on current and potential buyers of the ground source systems. Demographic information is needed on the size and characteristics of various potential buyer groups to support decisions regarding which target segments to pursue. There is also a need to quantify the reactions to communication alternatives and the priorities of potential buyers.

The second useful research direction is to explore the decision criterion and information needs of utility company managers who influence the decision to support conservation technology such as the GSHP. We may determine why some utilities do not support GSHP programs and perhaps remove the barriers to their participation. 



\section{REFERENCES}

Advertising Research Foundation. 1985. Focus Groups: Is sues and Approaches. Advertising Research Foundation, Inc., New York.

Bose, J. E. 1987. "Ground Source Heat Pump Applications," Proceedings of the Fifteenth Energy Technology Conference, pp. 455-462. Government Institutes, Inc., Washington, D.C.

Braud, H. J. 1987. "Commercial Ground-Coupled Heat Pump Applications and Case Studies," Proceedings of the Fifteenth Energy Technology Conference, pp. 463-476. Government Institutes, Inc., Washington, D.C.

Greenbaum, T. L. 1988. The Practical Handbook and Guide to Focus Group Research. D. C. Heath and Company, Lexington, Massachusetts.

Henisee, L. G. 1987. "Heat Pumps-R-Us," Proceedings of the Fifteenth Energy Technology Conference, pp. 555-561. Government Institutes, Inc., Washington, D.C. 


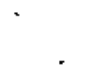


APPENDIX

STIMULUS CONCEPTS USED IN FOCUS GROUPS 


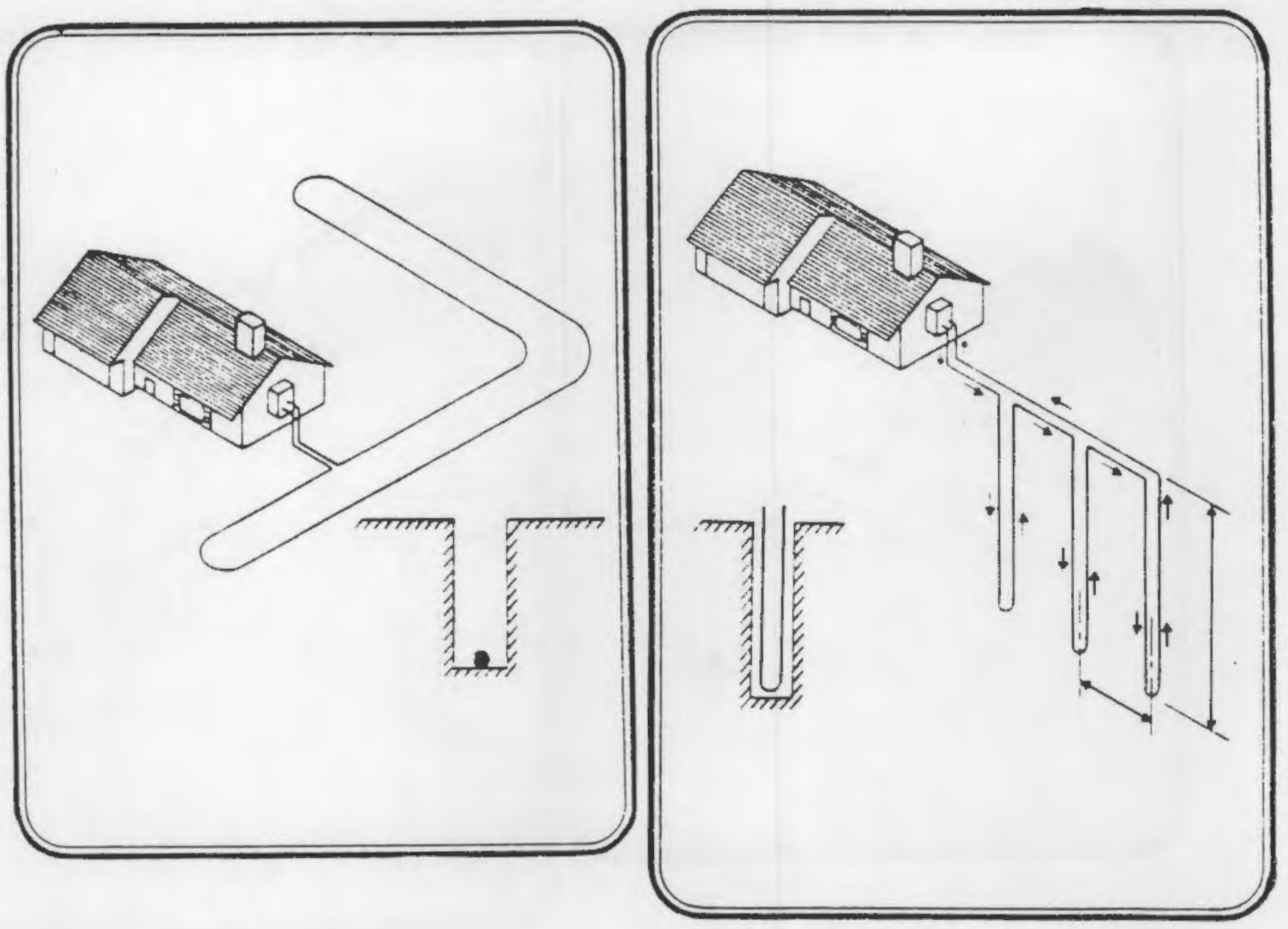

\section{SAVE $\$ 50$ EVERY MONTH}

The ground source heat pump can save you $\$ 50$ dollars a month in heating and air-conditioning bills. This remarkably efficient system can heat and air-condition your home using only about one third of the energy used by standard furnaces and air-conditioners. For most people this means a savings of at least $\$ 50$ a month. The more area you have to heat or cool, the more money you save.

The ground source heat pump is so efficient because it is able to transfer heat from the earth directly into your home. It does this by circulating water through an underground pipe and across an indoor heat pump. Just reverse the system to air-condition your home in the summer. This efficient system can recover the extra costs for installing the underground pipe in less than three years. After that, the savings are all yours. Invest in the ground source heat pump now, and you wi11 save $\$ 50$ a month from now on. 


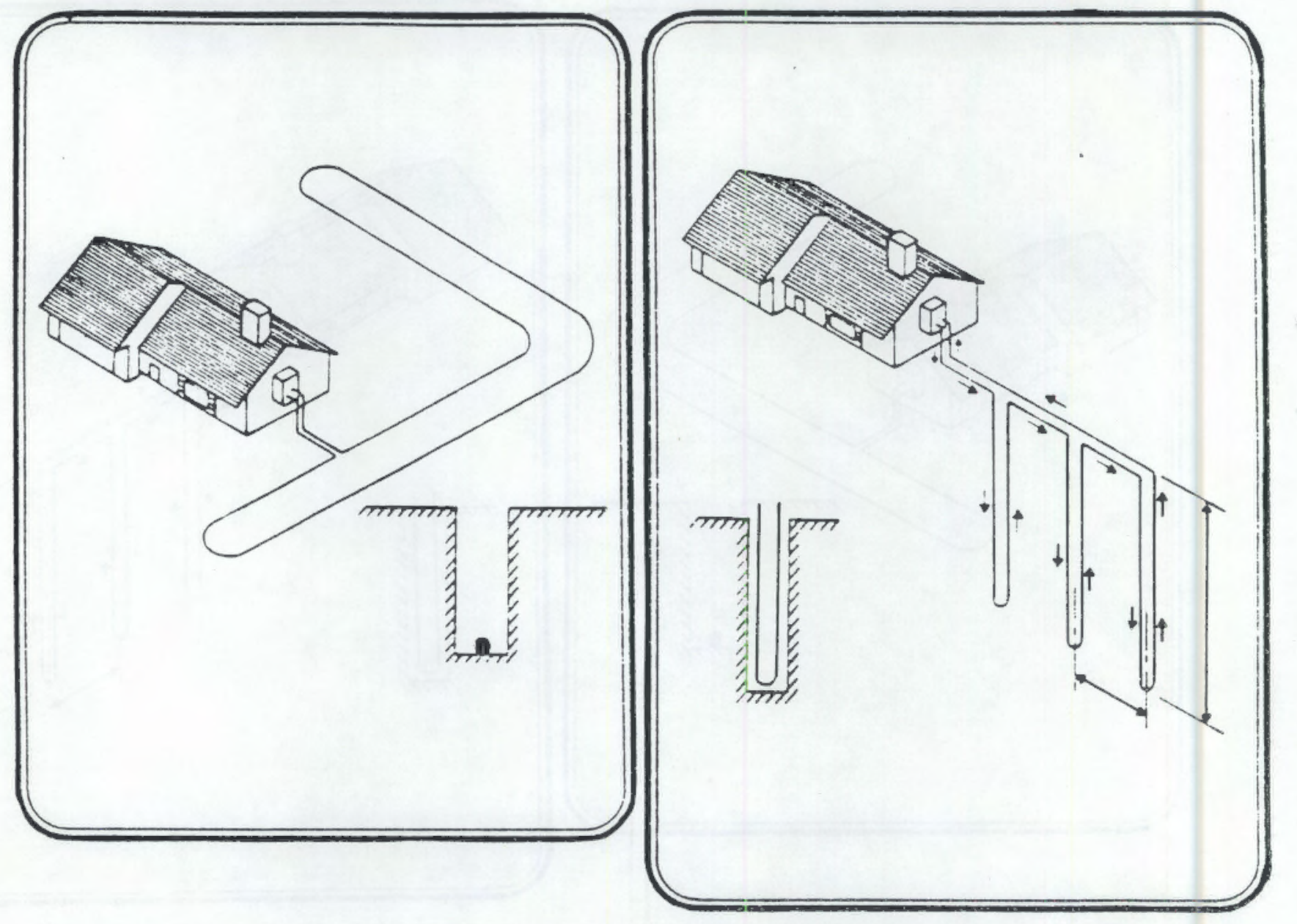

\section{ONE-THIRD THE COST}

The ground source heat pump is the most efficient system ever. Using this system you can heat and air-condition your home at about one third the cost of conventional systems. By circulating water through an underground pipe, the ground source heat pump is able to extract heat from the earth to heat your home. This system can be reversed with the flip of a switch in order to air-condition your home in the summer. This efficient system can recover the extra costs for installing the underground pipe less than three years. After that, the savings are all yours. Since the ground source heat pump uses only about one third of the energy needed for conventional systems, you will save money every month. 


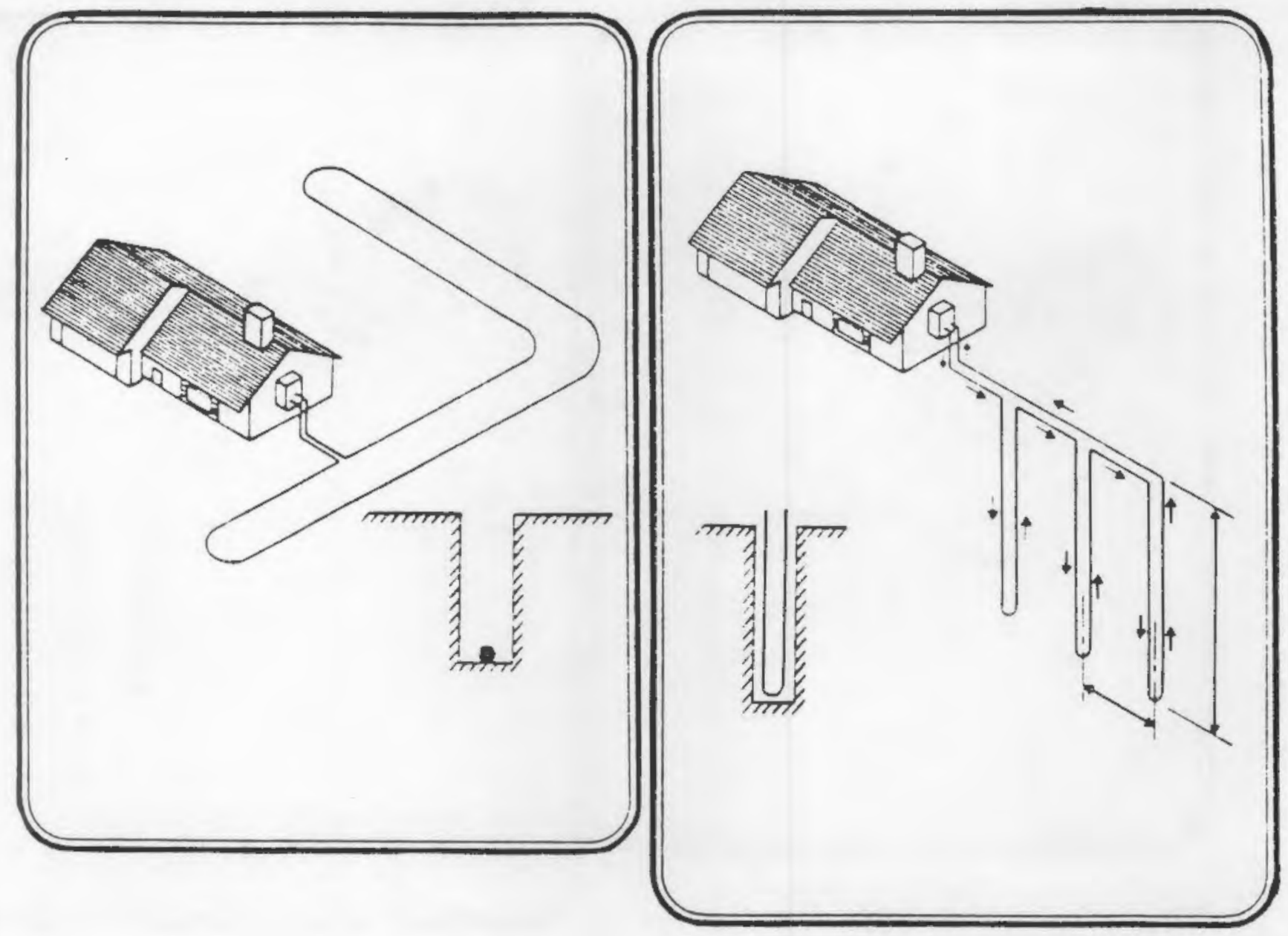

\section{A CLEAN AND NATURAL WAY TO CONTROL INDOOR AIR TEMPERATURE}

The ground source heat pump will give you natural temperature control from the earth year round. Traditional systems pollute your environment by burning fuel to make hot or cold air. The ground source heat pump is the natural way to transfer heat stored in the earth through underground pipes directly into your home. With the flip of a switch, the system can be reversed to cool your home in the summer. Some electricity is used to operate the heat pump, but only a fraction of the energy that traditional furnaces and air-conditioners use.

The ground source heat pump is the clean and natural way to heat and air-condition your home. The ground source heat pump is good for the environment, comfortable for your family, and will save you money every month. 


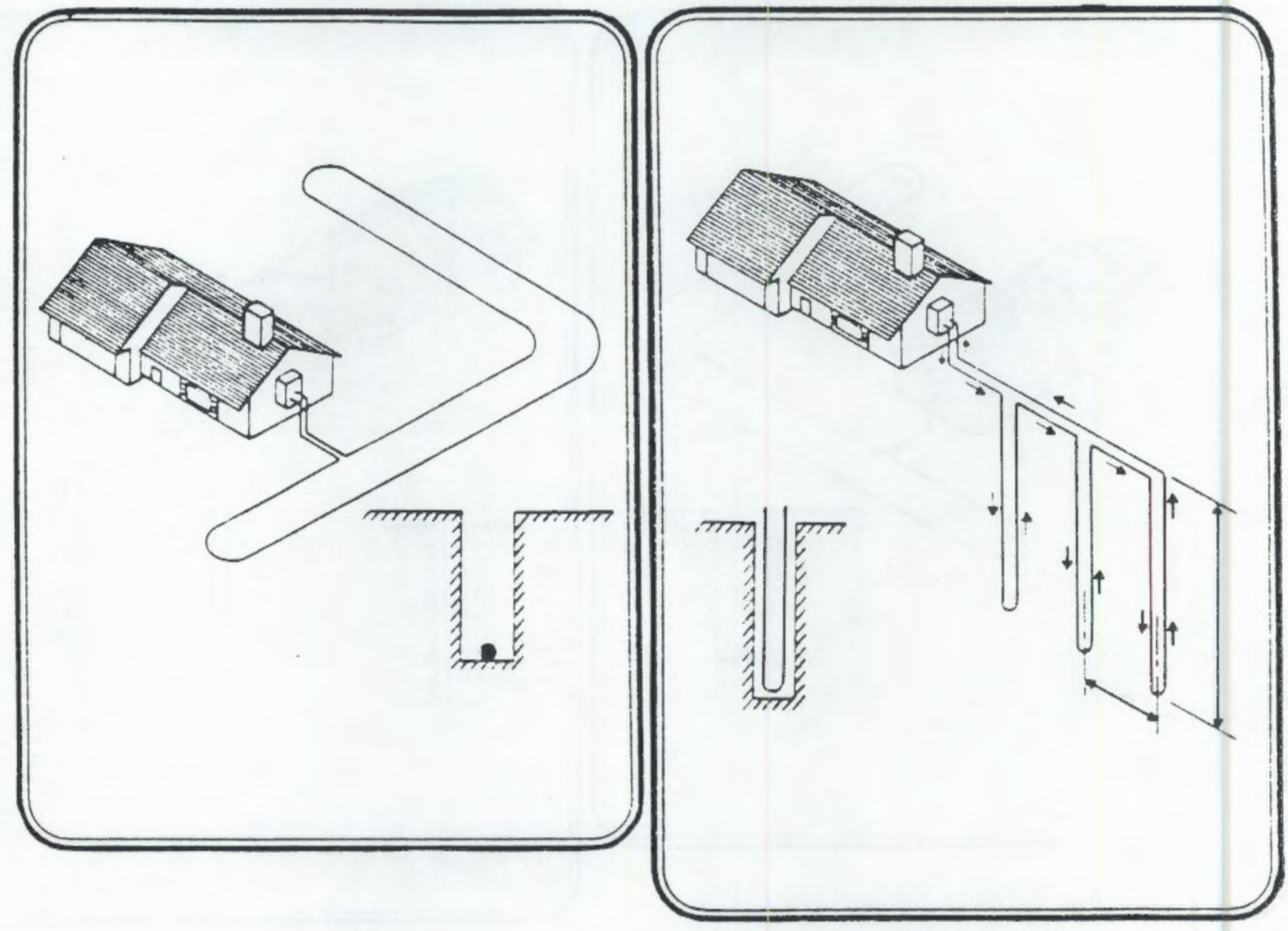

NEW TECHNOLOGY GIVES YOU ONE SYSTEM THAT CAN DO IT ALL

Why buy a separate furnace and air conditioner when there is one system that can handle the whole job? You can now have year round temperature control in your home using a high efficiency ground source heat pump. The ground source heat pump is quieter, cleaner, more reliable, and more efficient than the typical combination of a furnace and an air-conditioner.

The ground source heat pump transfers heat to and from an underground pipe in order to heat and cool your home. This single efficient system operates on about one third of the energy used by the combined furnace and air-conditioner systems of the past. Savings from lower energy bills will pay for installation of the underground pipe in less than three years.

The ground source heat pump is the ideal way to control air temperature in your home. You no longer have to depend on a patchwork of separate systems. Ask about the ground source heat pump. The most convenient way to make your house comfortable. 
PNL -6587

UC -95d

\section{DISTRIBUTION}

No. of

Copies

DFFSITE

50 F. Abe 1

Senior Economist

Office of Building \& Community Systems

U.S. Department of Energy

Forrestal Building, CE-11

1000 Independence Ave., S.W.

Washington, DC 20585

F. Ryan

Office of Building \& Commumity Systems

U.S. Department of Energy

Forrestal Building, CE-II

1000 Independence Ave., S.W.

Washington, DC 20585

T. Kapus

Office of Building \&

Community Systems

U.S. Department of Energy

Forrestal Building, CE-11

1000 Independence Ave., S.W.

Washington, DC 20585

J. Holmes

Office of Building \& Community Systems

U.S. Department of Energy

ForrestaT Building, CE-11

1000 Independence Ave., S.W.

Washington, DC 20585

10 DOE Office of Scientific and

Technical Information

T. Anyos

Manager, Commercial Development

Electric Power Research

Inst itute

$3412 \mathrm{Hi} T \mathrm{Tview}$ Avenue

P.0. Box 10412

Palo Alto, CA 94303
No. of

Copies

T. Dinan

Oak Ridge National Laboratory

P.0. Box $X$

Oakridge, TN 37831

K. Kazmer

Manager, Building Systems

Gas Research Institute

8600 West Bryn Mawr Avenue

Chicago, IL 60631

J. Lamontagne

Building 120

Brookhaven National Laboratory

Upton, NY 11973

\section{ONSITE}

DOE Rich] and Operations Office

J. J. Sutey

19 Pacific Northwest Laboratory

F. I. Johnson (3)

B. A. Garrett

S. A. Harkreader

E. J. Stenehjem

R. 0. Weijo

B. F. Roberson (5)

Publishing Coordination MH (2)

Technical Report Files (5) 

. 